\title{
STRATEGI NAFKAH PETANI JAGUNG LOKAL MADURA (Studi Kasus Desa Guluk-Guluk Kecamatan Guluk-Guluk Kabupaten Sumenep)
}

\author{
Safira Widyasmita ${ }^{1)^{*}}$, Isdiana Suprapti ${ }^{2)}$ \\ 1,2 Program Studi Agribisnis Fakultas Pertanian Universitas Trunojoyo Madura \\ Email : isdiana@trunojoyo.ac.id ${ }^{2)}$
}

\begin{abstract}
ABSTRAK
Tingginya angka petani jagung lokal di Desa Guluk-Guluk pada tahun 2018 tidak selaras dengan harapan kapitalisasi jagung hibrida yang akan menjadi penggerak perekonomian masyarakat Madura. Tahun 2018 pula Sumenep mencapai angka kemiskinan tertinggi di Madura. Penelitian ini bertujuan untuk menganalisis (1) Tipe modal nafkah; (2) Klasifikasi strategi nafkah; (3) Hubungan tipe modal terhadap klasifikasi strategi nafkah. Metode yang digunakan dalam penelitian yaitu analisis kualitatif dan korelasi. Hasil penelitian menunjukkan bahwa petani jagung lokal di Desa Guluk-Guluk menerapkan kelima tipe modal yaitu modal manusia, alam, sosial, finansial, dan fisik pada strategi nafkah ganda. Tingkat hubungan menunjukkan bahwa modal sosial dan modal alam memiliki nilai sig $<0,05$ yang berarti terdapat hubungan signifikan antara modal tersebut dengan strategi pola nafkah ganda.
\end{abstract}

Kata Kunci: jagung lokal, tipe modal, strategi nafkah, korelasi.

\section{PENDAHULUAN}

Jagung merupakan komoditas pangan penting selain komoditas padi. Menurut Fridayanti (2013) jagung lokal mayoritas ditanam di daerah Nusa Tenggara Timur, Sulawesi Selatan, dan Jawa Timur (Madura). Selama tahun 20132017 Kabupaten Sumenep mencapai angka produksi tertinggi dalam menanam jagung lokal dibandingkan kabupaten lain di Madura (Dinas Pertanian Provinsi Jawa Timur, 2017). Areal tanam jagung lokal Kabupaten Sumenep terbagi di tiga kecamatan yaitu Kecamatan Talango, Guluk-Guluk, dan Manding (Dinas Pertanian Tanaman Pangan Hortikultura Sumenep, 2018). Jagung lokal GulukGuluk pada tahun 2018 memiliki luas tanam paling rendah, namun mencapai produktivitas tertinggi sebesar 14,79 Ton.
Pada tahun 2018 pula Kabupaten Sumenep mencapai angka kemiskinan tertinggi sebesar 218.60 juta jiwa dibandingkan kabupaten lain di Madura (Badan Pusat Statistik Jawa Timur, 2018). Kemiskinan adalah salah satu faktor yang bisa menjelaskan persoalan nafkah rumah tangga, khususnya rumah tangga petani. Disamping itu, persoalan dalam pemenuhan kebutuhan penduduk miskin di Kabupaten Sumenep tidak hanya terbatas pada upaya memenuhi kehidupan seharihari, akan tetapi telah berkembang menjadi upaya untuk memperoleh nafkah rumahtangga yang lebih dengan mengembangkan beberapa alternatif strategi. Hal ini didukung dengan kearifan lokal petani madura yang berpendapat bahwa lebih berguna dan menguntungkan menanam jagung lokal, meskipun hasil penelitian Nurmansyah (2011) menyatakan 
bahwa usaha pertanian jagung lokal madura lebih rendah daripada jagung hibrida. Pendapatan petani lokal sebesar Rp 2.019.491/Ha, sedangkan hibrida sebesar Rp 5.349.747/Ha. Hal ini didukung hasil penelitian Suprapti (2014) yang menjelaskan bahwa jagung lokal secara alokatif sudah efisien, namun berbeda dengan Nikmah (2013) bahwa jagung hibrida secara alokatif belum efisien.

Berdasarkan sistem penghidupan lokal, budidaya jagung masih diterapkan secara tradisional dan turun temurun (Amzeri, 2018). Hal ini juga memicu kurangnya minat petani dalam mengadopsi jagung unggul varietas baru. Jagung tidak dapat dipisahkan dari kehidupan orang Madura, karena digunakan sebagai campuran beras untuk konsumsi masyarakat. Pada akhirnya petani jagung lokal harus mampu mengelola modal yang dimilikinya dengan berbagai cara untuk mencapai penghidupan yang diinginkan, sehingga mampu untuk memenuhi nafkah rumah tangganya. Berdasarkan penjelasan diatas, penelitian ini bertujuan untuk menganalisis tipe modal nafkah, strategi nafkah, dan hubungan tipe modal terhadap strategi nafkah.

\section{TINJAUAN PUSTAKA}

Teori konsep modal dari DFID (2001) disebut dengan prinsip Pentagon Asset. Pentagon Asset menghubungkan modal manusia, alam, sosial, finansial, dan fisik. Teori selanjutnya didukung oleh teori Klasik pada tahun 1950 yang dapat digambarkan dari persamaan berikut:

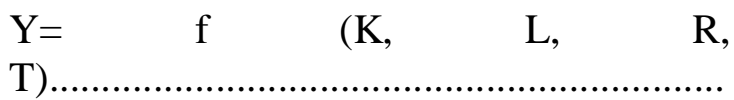

Y merupakan pendapatan nasional; $\mathrm{K}$ merupakan barang modal; $\mathrm{L}$ adalah jumlah tenaga kerja; $\mathrm{R}$ merupakan kekayaan alam; dan $\mathrm{T}$ adalah teknologi.

Menurut Ellis (2000) terdapat lima modal yang dapat dimiliki rumah tangga untuk perolehan nafkah. Meliputi modal manusia sebagai tenaga kerja dengan keterampilan yang dimiliki. Modal alam mencakup wujud air dan tanah. Ketiga modal sosial adalah jaringan sosial dan lembaga sosial. Kemudian modal keuangan meliputi kredit dan persediaan uang tunai. Tipe modal yang terakhir yaitu modal fisik meliputi mesin, alat-alat, dan berbagai benda fisik lainnya.

Selanjutnya sconees menggolongkan strategi nafkah (livelihood strategy) yang dapat dimanfaatkan oleh rumah tangga. Meliputi rekayasa sumber nafkah pertanian melalui intensifikasi dan ekstensifikasi. Selanjutnya pola nafkah ganda yang dilakukan dengan melaksanakan matapencaharian lain di bidang non-farm untuk menambah pendapatan rumah tangga. Strategi nafkah ketiga yaitu migrasi dengan melakukan perpindahan ke daerah lain di luar desanya, baik secara menetap maupun sirkuler.

Penelitian tentang strategi nafkah rumah tangga petani dilakukan oleh Liborang (2016), Sumartono (2018) dan Fridayanti (2013) yang ketiganya menjelaskan tentang strategi pola nafkah ganda yang banyak dipilih oleh petani. Penelitian sejenis juga dilakukan Samuel (2019) penelitian tersebut menunjukkan bahwa mayoritas responden melaksanakan kegiatan on-farm dengan memanfaatkan modal manusia untuk kegiatan di luar pertanian dan non pertanian. Selanjutnya penelitian yang menunjukkan tentang tipe modal nafkah ditunjukkan dengan berbagai unsur. Diantaranya yaitu modal fisik oleh Azalia (2015), modal finansial oleh Sembiring (2014), dan modal alam oleh Albore (2018) serta Wijayanti (2013). Selain itu penelitian mengenai analisis hubungan antara strategi nafkah dan tingkat pendapatan yang kuat dikemukakan oleh Setyawan (2017).

\section{METODE PENELITIAN}

Penelitian dilaksanakan di Desa Guluk-Guluk Kecamatan Guluk-Guluk Kabupaten Sumenep pada bulan Januari 
2020. Pemilihan lokasi dilakukan secara purposive dengan pertimbangan Desa Guluk-Guluk memiliki luas lahan terbesar untuk komoditas jagung (Dinas Pertanian Tanaman Pangan Hortikultura Sumenep, 2018). Metode penentuan sampel yang digunakan dalam penelitian ini dilakukan secara sengaja (purposive sampling). Sampel penelitian berdasarkan pada Sugiyono (2013) ukuran sampel yang layak dalam penelitian antara 30-500 responden. Responden untuk penelitian ini adalah 40 orang petani jagung lokal. Berikut data yang dikumpulkan (1) modal manusia yaitu pekerjaan keluarga dan keterampilan, (2) modal alam yaitu lahan dan air, (3) modal sosial yaitu jaringan sosial, rasa saling percaya, dan organisasi masyarakat, (4) modal finansial yaitu pendapatan dan tabungan, (5) modal fisik yaitu aset pertanian dan non pertanian, (6) serta klasifikasi sumber nafkah pertanian.

Metode analisis data, dimulai dengan menganalisis tipe modal nafkah dan strategi nafkah menggunakan analisis kualitatif yang bersifat deskriptif. Menurut Herdiansyah (2010) langkah awal yaitu pengumpulan data pada saat meneliti. Berikutnya dengan reduksi data atau disebut penggabungan segala bentuk data yang diperoleh. Langkah terakhir yaitu verifikasi data petani jagung lokal di Desa Guluk-Guluk Kecamatan Guluk-Guluk Kabupaten Sumenep. Dalam analisis ini menggunakan kode penilaian dalam kuisioner yaitu skor 1 untuk kriteria "iya" dan skor 2 untuk kriteria "tidak", serta menggunakan skala likert.

Selanjutnya dilakukan uji validitas, hasil menunjukkan bahwa nilai corrected item-total correlation seluruh variabel lebih dari 0,263 (r-tabel) yang dinyatakan semua butir tersebut valid. Sedangkan untuk reliabilitas dilihat pada nilai Cronbach's Alpha If Item Deleted. Semua butir pertanyaan tersebut memiliki nilai Cronbach's Alpha lebih dari nilai sig 0,5 jadi dapat dinyatakan bahwa semua butir dalam penelitian ini dinyatakan reliabel.
Terakhir menganalisis hubungan tipe modal nafkah terhadap strategi nafkah menggunakan analisis kuantitatif. Menurut Riduwan (2009), langkah-langkah dalam analisis korelasi dengan mengetahui interpretasi koefisien korelasi nilai Pearson Correlation. Pengambilan keputusan apabila nilai sig $<0,05$ maka H1 diterima, sebaliknya jika nilai sig > 0,05 maka $\mathrm{H} 0$ yang diterima, dengan hipotesis penelitian sebagai berikut:

H1 Diterima $=$ Terdapat hubungan antara tipe modal nafkah dan klasifikasi strategi nafkah petani jagung lokal Desa GulukGuluk.

H0 Diterima $=$ Tidak terdapat hubungan antara tipe modal nafkah dan klasifikasi strategi nafkah petani jagung lokal Desa Guluk-Guluk.

\section{HASIL DAN PEMBAHASAN}

\section{(1) Tipe Modal Nafkah Petani Jagung Lokal Desa Guluk-Guluk}

1. Aset utama yang dimiliki petani jagung lokal dalam mata pencahariannya yaitu tenaga kerja. Petani jagung lokal dalam memenuhi nafkah rumah tangganya tidak dilakukan dengan sendiri, namun bekerja sama dengan anggota keluarga yang lain. Sebanyak 25 kepala rumah tangga dengan anggota keluarga lainnya bekerja sebagai petani jagung lokal, begitupun dengan 11 orang responden lainnya yang juga bekerja dibantu oleh anggota keluarga lainnya. Keluarga yang bekerja juga didukung oleh keterampilan masing-masing individu dalam rumah tangga. Diketahui bahwa selain memiliki keterampilan dalam bidang pertanian, sebanyak 21 responden juga memiliki keterampilan lain diantaranya bisa mengendarai mobil, memasak kue, dan membuat batu bata/semen. Keterampilan tersebut yang akhirnya menjadi modal nafkah mereka untuk bekerja sampingan selain bertani. Pekerjaan sampingan tersebut juga diasah untuk dijadikan pekerjaan tambahan dengan menjadi sopir, 
pedagang makanan, dan juga buruh tani. Hal ini sejalan dengan penelitian Samuel (2019), yang juga menjadikan modal manusia dalam kegiatan on farm.

2. Kepemilikan modal alam memberikan akses kepada petani dalam mendapatkan penghidupan yang lebih baik. Hal ini juga terjadi di lokasi penelitian dengan mayoritas petani memiliki akses terhadap lahan sawah sendiri. Selaras dengan hasil penelitian Sumartono (2019), mengenai indikator kepemilikan lahan sawah.

Teknis pengairan yang sering dilakukan menggunakan mesin pompa air, dengan alat saluran pipa menggunakan tenaga listrik. Petani jagung lokal dalam penggunaan pompa air mendapatkan bantuan dari pemerintah desa berupa potongan harga sewa dan beberapa petani dapat menggunakan pompa air secara gratis dengan menyertakan kartu kemiskinan. Pembayaran berkisar antara 20.000-500.000 sesuai dengan solar yang dibutuhkan. Teknis pengairan lainnya yang dimiliki petani jagung lokal yaitu sumber air pertanian yang biasa disebut sumber danau Desa Guluk-Guluk. Sumber tersebut menjadi sistem irigasi yang dialirkan ke lahan-lahan sawah milik petani. Apabila musim kemarau tiba sumber danau tersebut menjadi kering, sehingga petani berganti dengan menggunakan sistem pompa air. Tentunya hal ini yang membedakan dengan cara tradisional yaitu memakai sistem irigasi sederhana.

3. Modal sosial adalah gambaran dalam jaringan sosial yang dimanfaatkan rumah tangga sebagai tumpuan untuk dapat bertahan hidup (Scoones, 1998). Petani jagung lokal dalam budidayanya sangat dekat dengan tipe modal ini dikarenakan seluruh responden mengenal baik tokoh masyarakat seperti ulama dan kepala desa. Hal ini dikarenakan seringnya bergotong royong antar desa dan seringnya diadakan perkumpulan masyarakat dalam kegiatan seperti kompolan, tahlilan, dan muslimatan. Namun sistem kerja desa di beberapa dusun kurang terstruktur sehingga menyebabkan kinerja RT dan RW tidak maksimal untuk masyarakat sehingga timbul tidak terjadinya jaringan sosial diantara RT dan RW di Desa GulukGuluk. Selanjutnya jaringan sosial petani jagung lokal dalam mengenal preman dengan nilai indeks sangat rendah, hal ini dikarenakan petani menjaga hasil panen dan budidayanya sendiri. Keunikannya beberapa petani menyatakan bahwa peran preman juga ada dalam membantu menjaga panen di desa tersebut, namun mereka tidak memiliki jaringan yang kuat atau tidak mengenal lebih mendalam preman tersebut. Begitupun peran aparat kecamatan dan aparat kabupaten yang ikut menjaga apabila terdapat permasalahan dalam keamanaan maupun keresahan yang mengganggu masyarakat, akan tetapi petani tidak mengenal dan memiliki jaringan sosial dengan tokoh tersebut. Modal sosial lainnya merupakan rasa saling percaya yang dimiliki oleh petani jagung lokal di Desa Guluk-Guluk.

Petani jagung lokal memiliki rasa saling percaya dengan warga sekitar dikarenakan pada saat sedang membutuhkan bantuan, warga sekitar yang membantu petani dalam budidaya maupun dalam permasalahan hidup sehari-hari. Rasa saling percaya petani jagung lokal juga tertuju kepada kepala desa, tokoh masyarakat, dan ulama dikarenakan dengan adanya tokoh tersebut kearifan lokal terjalin dengan sangat erat. Beberapa petani juga memiliki rasa saling percaya dengan adanya preman di kampung halaman mereka, namun untuk rasa saling percaya kehidupan sehari-hari lainnya sangat rendah yang dibuktikan dengan nilai indeks yang sangat kecil. Terbentuknya jaringan sosial dan rasa saling percaya petani jagung lokal juga didukung dengan organisasi yang mereka ikuti. Seluruh responden menyatakan bahwa mereka mengikuti kelompok keagamaan yang dalam bahasa madura disebut dengan kompolan atau muslimatan. 
Hal ini berbanding terbalik dengan penelitian Azalia (2015), bahwa tingkat penguasaan modal sosial rumah tangga petani cenderung rendah disebabkan kesibukan rumah tangga petani setiap harinya untuk ikut dalam kegiatan organisasi dan sosial.

4. Modal finansial berupa aset ekonomi yang berasal dari pendapatan, tabungan, arisan, maupun ternak yang dimiliki. Pendapatan rumahtangga petani jagung lokal di Desa Guluk-Guluk sebagian besar 500.000-5.000.000 per bulan. Sedangkan pengeluarannya berkisar 3.500.000-5.000.000 setiap bulannya. Selanjutnya kepemilikan aset terbesar yaitu dimiliki oleh 1 orang petani dengan pendapatan > 20.000.000 dikarenakan selain bertani juga memiliki bisnis. Hasil penelitian ini selaras dengan penelitian Samuel (2019) dan Sugiarti (2009) mengenai pola konsumsi hasil taninya.

Kepemilikan modal finansial juga dikategorikan dalam kepemilikan tabungan dan kegiatan arisan, mayoritas responden tidak menabung di bank tetapi lebih mengikuti arisan sebagai bentuk investasi. Hal ini dikarenakan untuk menabung, biaya awal yang dikeluarkan lebih besar sehingga petani tidak mampu untuk membayar, akan tetapi untuk mengikuti arisan dengan biaya 5.000-10.000 per bulan petani lebih sanggup untuk membayarnya. Hal ini sejalan dengan penelitian Sembiring (2014) yang menjelaskan bahwa menabung tidak menjadi prioritas rumah tangga.

5. Modal fisik menggambarkan kepemilikan aset yang dimiliki. Modal fisik dalam penelitian dibedakan menjadi dua yaitu kepemilikan aset pertanian dan non pertanian. Salah satu penentu produksi jagung lokal adalah dengan peralatan dan mesin yang dimiliki. Petani jagung lokal mayoritas memiliki cangkul sendiri dalam budidayanya, sedangkan jika cangkul yang dimiliki rusak, mereka bergantian dan meminjam satu sama lain. Mesin yang digunakan adalah traktor dan penggiling jagung, yang digunakan dengan cara menyewa. Hal ini dikarenakan petani tidak mampu untuk membeli traktor dan penggiling jagung. Penyewaan dilakukan dengan biaya antara 90.000-100.000. Sedangkan jika petani jagung lokal mengenal sangat dekat pemilik traktor atau pemilik penggiling jagung, maka penyewaannya akan digratiskan. Hal ini selaras dengan penelitan Sugiarti (2009) bahwa petani jagung lokal memiliki kearifan lokal tinggi dalam penyediaan sarana input maupun sarana fisik dalam budidaya yang dilakukan.

Aset non pertanian yang dimiliki diantaranya meliputi kendaraan, penunjang alat dalam rumah dan perhiasan. Berdasarkan hasil penelitian petani jagung lokal di Desa Guluk-Guluk menggunakan sepedamotor untuk keperluan mencari nafkah, sedangkan tidak ada yang memiliki mobil kecuali pekerjaan sampingannya menjadi seorang sopir untuk mencari nafkah tambahan. Sedangkan untuk penunjang di dalam rumah seperti tv, kulkas, dan kipas angin sangat jarang petani jagung lokal memilikinya. Masyarakat juga lebih banyak mencuci sendiri baju kotornya dibandingkan menggunakan mesin cuci. Aset yang disimpan untuk keperluan saving salah satunya perhiasan. Berbanding terbalik dengan penelitian Azalia (2015) bahwa modal fisik tidak diperlukan untuk mendukung mata pencaharian seperti halnya kepemilikan barang berharga.

\section{(2) Klasifikasi Strategi Nafkah Petani Jagung Lokal Desa Guluk-Guluk}

Strategi nafkah merupakan cara yang dilakukan rumah tangga petani jagung lokal untuk memenuhi kebutuhan hidupnya. Maka dari itu perlu adanya pengklasifikasian strategi nafkah agar petani jagung lokal dapat mengetahui strategi yang tepat dalam mencukupi nafkah rumah tangganya selain menanam jagung lokal. Sebanyak 2 responden mencari nafkah tambahan dengan bekerja 
di luar kota dan luar negeri dalam jangka waktu panjang dan menetap dengan menjadi buruh bangunan kota lain. Selanjutnya Rekayasa sumber nafkah pertanian berjumlah 14 responden, dengan bekerja hanya dalam sektor pertanian, mereka menanam jagung lokal untuk konsumsi sendiri, dijual, dan untuk pakan ternak. Mayoritas sebanyak 24 orang responden menjawab pekerjaannya pada pola nafkah ganda. Sesuai dengan tipe modal yang dimiliki diantaranya memiliki keterampilan dibidang pertanian dan non pertanian, memiliki nilai sosial yang tinggi, modal alam yang memadai, memiliki modal finansial dengan memperoleh pendapatan sebagai petani

Tabel 1

Hubungan Tipe Modal Nafkah dan Strategi Nafkah

\begin{tabular}{lll}
\hline Sig (2-tailed) & Sig & Pearson \\
\hline Y & - & 1 \\
X1 (Modal Manusia) & 0,235 & 0,192 \\
X2 (Modal Alam) & 0,028 & 0,347 \\
X3 (Modal Sosial) & 0,000 & 0,647 \\
X4 (Modal Finansial) & 0,992 & 0,002 \\
X5 (Modal Fisik) & 0,503 & 0,109 \\
\hline
\end{tabular}

Sumber : Data Primer diolah, 2020

Berdasarkan Tabel 2 dapat

diketahui bahwa modal alam dan modal sosial menunjukkan nilai Sig < 0,05 yang berarti $\mathrm{H} 1$ diterima. Hal ini menunjukkan terdapat hubungan yang signifikan antara modal sosial dan modal alam terhadap strategi nafkah ganda petani jagung lokal di Desa Guluk-Guluk. Faktor alam sangat dibutuhkan dalam budidaya tanaman jagung lokal karena sangat bergantung pada luas lahan, tanah, dan air pada daerah tersebut. Nilai pearson modal alam yaitu 0,347 berarti memiliki hubungan sangat rendah. Selanjutnya yaitu modal sosial, petani jagung lokal menanam jagung tersebut dikarenakan adanya faktor-faktor sosial diantaranya jika terdapat warga atau masyarakat sekitar sedang kesusahan dalam rumah tangga maka mereka memberikan jagung lokal yang dimilikinya, dengan cara menjual hasil jagung lokal tersebut untuk memberikan dan non petani, serta memiliki modal fisik yang mendukung. Penelitian ini sejalan dengan Fridayanti (2013) dan Liborang (2016) yang respondennya menerapkan pola nafkah ganda dalam strategi nafkah kehidupannya dengan berbagai tipe modal yang dimiliki.

\section{(3) Hubungan Tipe Modal Nafkah terhadap Klasifikasi Strategi Nafkah Petani Jagung Lokal Desa Guluk- Guluk} terhadap strategi nafkah dengan menggunakan nilai Pearson yang telah dihasilkan pada Tabel 2. 
dikarenakan mereka mengenal pemiliknya maka penyewaan digratiskan dengan membawa kartu tanda miskin. Begitupun dengan modal manusia, hanya diperlukan untuk awal penanaman dan panen pada budidaya yang dilakukan dan memiliki keterampilan di bidang non pertanian. Hasil analisis berbanding terbalik dengan penelitian Setyawan (2017) tentang analisis hubungan strategi nafkah dan taraf hidup rumah tangga petani bahwa terdapat hubungan yang signifikan antara modal finansial yaitu pendapatan terhadap strategi nafkah ganda.

\section{PENUTUP}

Berdasarkan tipe modal petani jagung lokal Desa Guluk-Guluk. (1) modal manusia yang dimiliki yaitu anggota keluarga yang bekerja adalah mayoritas kepala rumah tangga dibantu anggota keluarga yang lain serta memiliki keterampilan terbesar di bidang pertanian dan non pertanian. (2) modal alam, seluruh petani memiliki lahannya sendiri dan untuk pengairannya mayoritas menggunakan sistem pompa air. (3) modal sosial dengan komponen jaringan dan saling percaya menunjukkan nilai indeks tertinggi yaitu pada tokoh masyarakat, ulama, kepala desa, dan warga sekitar. (4) Keempat modal finansial yaitu pendapatan yang diperoleh dari sektor on-farm dan non pertanian, namun pendapatan yang diperoleh tidak sebesar pengeluaran setiap bulannya. (5) Terakhir yaitu modal fisik, sebanyak 38 orang petani memiliki cangkul sendiri, 40 petani menyewa mesin penggilingan jagung, 33 menyewa traktor. Sedangkan modal fisik non pertanian yang dimiliki yaitu TV, emas, sepedamotor, kipas angin, dan kulkas. Selanjutnya bentuk strategi nafkah menunjukkan hasil bahwa strategi nafkah ganda menjadi pilihan petani jagung lokal Guluk-Guluk untuk memenuhi nafkah keluarga. Hasil analisis menunjukkan bahwa variabel modal alam dan modal sosial memiliki nilai sig $<0,05$ yang berarti $\mathrm{H} 1$ diterima yang berarti terdapat hubungan signifikan antara modal alam dan modal sosial terhadap nafkah ganda petani jagung lokal di Desa Guluk-Guluk.

\section{UCAPAN TERIMA KASIH}

Puji syukur alhamdulillah penulis panjatkan kehadirat Allah SWT. Penulis mengucapkan terima kasih yang sebesarbesarnya kepada semua pihak yang telah membantu terutama orang tua dan juga dosen pembimbing skripsi Ibu Dr. Isdiana Suprapti, SP., MM, dosen pembimbing seminar Bapak Andrie Kisroh Sunyigono S.P., M.P., Ph.D dan dosen penguji skripsi Bapak Mokh. Rum, SP., MP yang telah membantu dalam penyelesaian skripsi ini.

\section{DAFTAR PUSTAKA}

\section{Pustaka Primer (Jurnal)}

Abebe, A. 2018. Review on Rural Livelihood Diversification Strategies in Ethiopia. International Journal of Current Research and Academic Review, Vol.6, No.7: 81-86.

Albore, A. 2018. Review On Determinan Of Sustainable Rural Livelihood Diversification Of Small Holder Farmers in Ethiopia. International Journal of Advanced Research, Vol.6, No.2: 251-259.

Amzeri, A. 2018. Tinjauan Pengembangan Pertanian Jagung di Madura dan Alternatif Pengolahan Menjadi Biomaterial. Rekayasa, Vol.11, No.1: 74-86.

Dharmawan, A. H. 2007. Sistem penghidupan dan nafkah pedesaan. Jurnal Transdisiplin Sosiologi, Komunikasi, Dan Ekologi Manusia, Vol.1, No. 2: 169-192.

Ellis, F. 2000. Rural Livelihood Diversity in Developing Countries: Evidence and Policy Implications. Overseas Development Institute, London, Vol.1, No 40: 2-8.

Fridayanti, N., \& Dharmawan, A. H. 2013. Analisis Struktur dan Staretegi Nafkah Rumah tangga Petani Sekitar Kawasan Hutan Konservasi di Desa 
Cipeuteuy, Kabupaten Sukabumi. Jurnal Sosiologi Pedesaan, Vol.1, No.1: 26-36.

Kartika, T. 2018. Pengaruh Jarak Tanam terhadap Pertumbuhan dan Produksi Jagung (Zea Mays L) Non Hibrida di Lahan Balai Agro Teknologi Terpadu (ATP). Sainmatika: Jurnal Ilmiah Matematika Dan Ilmu Pengetahuan Alam, Vol.15, No.2: 129.

Liborang, H. F. 2016. Strategi Nafkah Rumah tangga Petani ( RTP ) Transmigrasi di Kampung Bumi Raya dan Kampung Wadio Distrik Nabire Barat , Kabupaten Nabire. Jurnal Fapertanak, Vol.1, No.1: 11-18.

Nikmah. 2013. Analisis Produktivitas Usahatani Jagung Hibrida di Kabupaten Sumenep. Agriekonomika, Vol.2, No.2: 96-107.

Samuel, O. O. 2019. Analysis of Rural Livelihood Diversification Strategies Among Maize Farmers in North West Province of South Africa. International Journal of Entrepreneurship, Vol.23, No.2: 111.

Sembiring. 2014. Resiliensi Nafkah Rumah tangga Petani Di Kawasan Rawan Bencana Rob Kecamatan Kampung Laut, Kabupaten Cilacap.Jurnal Sosiologi Pedesaan, Vol.2, No.1: 30-42.

Setyawan, L., Satria, A., Sains, D., Dan, K., Masyarakat, P., \& Manusia, F. E. 2017. Hubungan Pengembangan Wisata dengan Strategi Nafkah dan Taraf Hidup Rumah tangga Nelayan Desa Karimunjawa. Jurnal Sains Komunikasi Dan Pengembangan Masyarakat, Vol.1, No.2: 167-182.

Sugiarti, T., \& Hayati, M. 2009. Komoditas Jagung Varietas Baru. Jurnal Embryo, Vol.6, No.1: 35-46.

Sugiharto, A., Hartoyo, H., \& Muflikhati,

I. 2016. Strategi Nafkah dan Kesejahteraan Keluarga Pada Keluarga Petani Tadah Hujan. Jurnal Ilmu Keluarga Dan Konsumen, Vol.9,
No.1: 33-42.

Sumartono, E., \& S, Y. A. 2018. Strategi Nafkah Petani Sawit di Desa Penarik Kecamatan Penarik Kabupaten Mukomuko. Jurnal Mahatani, Vol.1, No.2: 80-95.

Suprapti, I.,Darwanto, H. D. 2013. Efisiensi Produksi Petani Jagung Madura dalam Mempertahankan Keberadaan Jagung Lokal. Agriekonomika, Vol.2, No.1: 96-107.

Teriola, E. W., Girsang, W., \& Wenno, N. F. 2018. Strategi Nafkah Dan Kemiskinan Di Kepulauan Tanimbar ( Studi Kasus Rumah tangga Petani Di Desa Lelingluan Kecamatan Tanimbar Utara Kabupaten Kepulauan Tanimbar ) ( Case Study Of Farmer Households In The Vilage. Jurnal Agribisnis Kepulauan, Vol.6, No 2: 199-211.

Widodo, S. 2011. Strategi Nafkah Berkelanjutan Bagi Rumah Tangga Miskin di Daerah Pesisir. Makara Sosial Humaniora, Vol. 15, No.1:1020.

Wijayanti. 2013. Strategi Peningkatan Kesejahteraan Masyarakat Nelayan Kecamatan Pademawu Kabupaten Pamekasan. Agriekonomika, Vol.2, No.2: 139-152.

Buku Teks

Azwar, S. 2001. Metode Penelitian, Edisi I, cet. 3. Pustaka Pelajar. Yogyakarta

Herdiansyah, H. 2010. Metode Penelitian Kualitatif untuk Ilmu-ilmu Sosial. Salemba Humanika. Jakarta.

Mantra, I.B. 2003. Demografi Umum. Pustaka Pelajar Offset. Yogyakarta.

Riduwan. 2009. Skala Pengukuran Variabel-variabel Penelitian.

Alfabeta. Bandung.

Sugiyono.2013. Metode Penelitian Kuantitatif Kualitatif Dan $R \& D$. Alfabeta. Bandung.

Yuliati.2003.Sosiologi Pedesaan. Lappera Pustaka. Yogyakarta.

Prosiding

Arifin, Z., Istiqomah, N., \& Fatmawati. 
2010. Pengembangan Jagung Varietas Lokal Sumenep. Prosiding Pekan Serealia Nasional. Balai Penelitian Tanaman Serealia.

Skripsi/Tesis/Disertasi

Azalia, Natasha, Rebecca. 2015. Pengaruh Strategi Nafkah Rumah Tangga Petani Padi Sawah Terhadap Tingkat Kesejahteraan (Kasus Desa Ligarmukti, Kecamatan Klapanunggal, Kabupaten Bogor). Skripsi. Institut Pertanian Bogor. Bogor.

Nurmansyah, E. 2011. Analisis Pendapatan Dan Faktor-Faktor Yang Mempengaruhi Tingkat Produksi Usahatani Jagung Pada Lahan Kering. (Studi Kasus Di Desa Lomaer, Kecamatan Blega, Kabupaten Bangkalan, Madura, Jawa Timur). Tesis. Unibrawyuliati.

Saleh, Endang. 2014. Strategi Penghidupan Penduduk Sekitar Danau Limboto Provinsi

Gorontalo.Disertasi.Universitas Negeri Gorontalo.

Artikel/Paper Internet

Ashley, C., \& Carney, D. 1999. Sustainable Livelihoods Analysis: Lessons form early experience. In Department for International development. London.

DFID. 1999. Sustainable Livelihoods Guidance Sheets. In Departement for International Development (2.1). London.

Sconees, I. 1998. Sustainable rural livelihoods. In IDS Working Paper.

Badan Pusat Statistik. 2018. Penduduk Miskin Kabupaten di Jawa Timur. 